Jan Stievermann

\title{
Prophecy, Piety, and the Problem of Historicity
}

\author{
Interpreting the Hebrew Scriptures in Cotton Mather's 'Biblia Americana'
}

[Prophetie, Frömmigkeit und das Problem der Historizität. Deutungen der Hebräischen Bibel in Cotton Mathers Biblia Americana .]

Veröffentlicht auf Englisch.

Das Buch bietet die erste übergreifende Untersuchung von Cotton Mathers bislang unveröffentlichter Biblia Americana

JAN STIEVERMANN

Prophecy, Piety, and the Problem

of Historicity

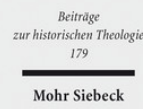

2016. XIII, 493 Seiten. BHTh 179

ISBN 978-3-16-154271-8

DOI 10.1628/978-3-16-154271-8

eBook PDF 129,00€

ISBN 978-3-16-154270-1

Leinen $129,00 €$
(1693-1728), dem frühesten im britischen Nordamerika verfassten Bibelkommentar. Im Zentrum steht Mathers Ringen um das traditionelle christliche Verständnis der hebräischen Bibel als Altes Testament. Jan Stievermann geht Mathers

Auseinandersetzung mit der Frage nach, in wieweit typologische und allegorische Lesarten angesichts eines wachsenden Bewusstseins von der Historizität der Schrift aufrecht zu erhalten bzw. zu revidieren sind. Andere zentrale Themenkomplexe sind Mathers Beiträge zu den zeitgenössischen Debatten um die Legitimität der christlichen Interpretation der Propheten, sowie um Autorschaft, Herkunft und Textgenre umstrittener Bücher wie Prediger Salomo und Hohelied. Der Autor bietet faszinierende Einblicke in eine immer noch zu wenig erforschte Phase der Bibelinterpretation, die gleichzeitig traditionalistisch und innovativ, apologetisch, fromm und offen für neue Arten der historisch-kritischen Methode war. Darüber hinaus eröffnet Mathers Exegese neue Einsichten in die Entwicklung der puritanischen Theologie und Identität.

Jan Stievermann Born 1975; 2005 PhD in American Studies from the University of Tübingen; since 2011 Professor for the History of Christianity in the USA at the University of Heidelberg.

Jetzt bestellen:

https://mohrsiebeck.com/buch/prophecy-piety-and-the-problem-of-historicity-9783161542718?no cache=1 order@mohrsiebeck.com

Telefon: +49 (0)7071-923-17

Telefax: +49 (0)7071-51104 